\title{
Rétif De La Bretonne, La Malédiction paternelle
}

\section{Regina Bochenek-Franczakowa}

\section{(2) OpenEdition}

\section{Journals}

\section{Édition électronique}

URL : https://journals.openedition.org/studifrancesi/45910

DOI : 10.4000/studifrancesi.45910

ISSN : 2427-5856

\section{Éditeur}

Rosenberg \& Sellier

\section{Édition imprimée}

Date de publication : 1 octobre 2007

Pagination : 449

ISSN : 0039-2944

\section{Référence électronique}

Regina Bochenek-Franczakowa, «Rétif De La Bretonne, La Malédiction paternelle », Studi Francesi [En ligne], 152 (LI | II) | 2007, mis en ligne le 30 novembre 2015, consulté le 24 novembre 2021. URL http://journals.openedition.org/studifrancesi/45910; DOI : https://doi.org/10.4000/studifrancesi. 45910

Ce document a été généré automatiquement le 24 novembre 2021.

\section{(c) (i) () $९$}

Studi Francesi è distribuita con Licenza Creative Commons Attribuzione - Non commerciale - Non opere derivate 4.0 Internazionale. 


\title{
Rétif De La Bretonne, La Malédiction paternelle
}

\author{
Regina Bochenek-Franczakowa
}

\section{RÉFÉRENCE}

RÉTIF DE LA BRETONNE, La Malédiction paternelle, Édition critique par Pierre TESTUD, Paris, Honoré Champion, 2006 («L’Âge des Lumières», 32), pp. 499.

1 La réédition moderne de La Malédiction paternelle de Rétif, ouvrage jusqu'ici introuvable et peu connu, est un événement important pour la connaissance de l'œuvre de cet écrivain. Pierre Testud, en illustre spécialiste, prend soin de nous guider à travers les méandres de la production prolifique de Rétif, dans le but d'y situer La Malédiction. Grâce à ses indications, le lecteur peut donc considérer ce roman à la fois dans son autonomie et dans sa qualité de partie d'un ensemble autobiographique où les personnages, les motifs et les situations forment un réseau intertextuel fort dense. La lecture de ce roman par lettres à voix multiples n'est, de prime abord, pas aisée. C'est que Rétif y procède au brassage de tons, formes et registres. La forme épistolaire s'y complicate par l'insertion du roman-mémoires et du journal intime; les histoires se chevauchent, au gré des blocs de correspondance que le protagoniste prépare avant de les envoyer à son ami promu à devenir son «exécuteur testamentaire». La disparate des histoires est renforcée par la fragmentation, l'inachèvement des textes, des «blancs» et lacunes dont certains sont indéchiffrables.

2 Ce roman touffu se caractérise pourtant par une cohérence interne, désignée par le titre. D'un côté, la malédiction paternelle, thème fort à la mode à l'époque, assure la «cohésion narrative» à ce récit fragmentaire (pp. 14-15); de l'autre, ce thème sublime la conscience malheureuse de l'écrivain: se projeter dans la figure du «fils maudit» permet de se libérer de la culpabilité de s'être écarté de son destin de paysan. En même temps, c'est pour la première fois que Rétif se projette dans la fiction en tant qu'écrivain. Le protagoniste, au nom caché sous l'initiale $\mathrm{N}^{* * * * * *}$ et le nom imaginaire 
de Dulis, est un personnage dont l'occupation principale est d'écrire: des lettres, un journal intime, mais aussi des ouvrages dont les titres évoqués, quoique dissimulés par des initiales, se laissent reconnaître pour être ceux de Rétif lui-même. Ce roman, remarque P. Testud, constitue le moment crucial qui montre l'écrivain s'engageant dans la voie de l'autobiographie proprement dite (p. 19). La Malédiction paternelle illustre d'une manière patente les phénomènes à la fois d'hybridisation de la forme et d'assombrissement du contenu, qui vont marquer progressivement le roman français dans les deux dernières décennies du siècle des Lumières. 